\title{
A via proteolítica dependente de ubiquitina/proteassoma
}

Resumo Nas células eucariotas a principal via de degradação de proteínas de semi-vida curta é não lisossomal e é dependente de ATP e de ubiquitina. Proteínas que regulam determinadas funçōes e que por isso existem por curtos períodos de tempo, proteínas danificadas, ou proteínas com erros de síntese são marcadas para degradação através da ligação de cadeias de poli- ubiquitina. As proteínas poli-ubiquitiladas são reconhecidas e degradadas pelo proteassoma 265 . A via proteolítica dependente de ubiquitina funciona no citoplasma e no núcleo das células, sendo também responsável pela degradação de proteínas associadas ao retículo endoplasmático, após o seu o retro-transporte para o citoplasma.

\section{Introdução}

A existência de degradação das proteínas intracelulares foi sugerida por Rudolf Schoenheimer nos anos 30 (1). Em 1953 surge uma publicação que mostra que a proteólise intracelular é dependente de energía métảbólicả (2). Nós anos 70 tornou-se evidente que a dégradação de proteínas intracelulares é altamente selectiva e está envolvida na regulaçăo da concentraçăo de certós enzimás (3). De início fơ difícil de cómpreender a nécessidaade da próteólise intracelular, uma vez que o que estava em causa era a hidrólise de ligações peptídicas das proteínas, que se pensava serem moléculas estáveis. Hoje em dia é evidente que o controlo do nível de determinadas proteínas no interior das células durante certos processos celulares, bem como a eliminação de protel=nas com erros de síntese, proteínas não funcionais e polipéptidos desnaturados, cuja acumulação poderia tornar-se tóxica, só pode ocorrer se existir proteólise selectiva. A descoberta da via proteolítica dependente de ubiquitina veio revolucionar a forma de olhar a degradação de proteínas intracelulares.
A ubiquitina foi descoberta em 1975 (4). Isolada a partir do timo, na altura foi-lhe atribuída a função de hormona capaz de induzir diferenciação dos linfócitos $B$. Dois anos mais tarde, é descrita como associada à histona $2 \mathrm{~A}(5)$. 0 terminal $C$ da ubiquitina encontrava-se ligado ao grupo e da cadeia lateral da lisina 119 da histona 2A através de uma ligação isopeptídica. A relação da ubiquitina com a proteólise intracelular só viria a ser publicada em 1980, resultante do trabalho do professor Avram Hershko (Instituto de Tecnologia de Haifa, Israel) que no ano lectivo de $1977 / 78$ se encontrava de sabática no laboratório de Irwin Rose (Fox Chase Cancer Center em Filadélfia) juntamente com Aaron Ciechanover, na altura seu estudante de doutoramento. Trabalho que valeu a estes três investigadores o prémio Nobel da Química 2004.

Avram Hershko desde o tempo do seu pós doutoramento (1969-1971) estava interessado em entender os processos que regulavam a concentração da tirosina-aminotransferase. Como naquele tempo um assunto muito estudado era a regulação da síntese das proteínas, Hershko, tentando evitar uma aborda- gem tão competitiva, decidiu estudar a forma como este enzima era degradado. Tomando vantagem do sistema proteolítico dependente de ATP anteriormente identificado em extractos de reticulócitos por Etlinger e Goldberg (6), Hershko e Ciechanover resolveram analisar bioquimicamente este sistema. Começaram por separar as proteínas do lisado em duas fraç̧ŏes: a fracçăo de proteínas que não adsorvia a uma resina de DEAE-celulose (fracçăo 1) e a fracção das proteínas adsorvidas à resina eluídas com clopeto de sódio (fracçầo 2). curiosamente, a fracção 2 não apresentava praticamente actividade proteolítica dependente de ATP quando comparada com os lisados iniciais. Em estudos de reconstituiçẵo, ou seja, quando a fracção 1 era adicionada à fracção 2, observava-se o restabelecimento da actividade proteolítica dependente de ATP. O componente responsável pelo restabelecimento da actividade era uma proteína termoestável de pequenas dimenső̉es existente na fracçăo 1 (7) na altura designado por APFI (ATP-dependent proteolysis factor). Wilkinson e colegas em 1980 (8) demonstraram que

\footnotetext{
* Departamento de Química e Bioquímica, Faculdade de Ciências e Tecnologia e Centro de Biomedicina Molecular e Estrutural, Universidade do Algarve Campus de Gambelas, 8000-117 Faro, E-maili pcramos@ualg.pt
} 
figura 1 - Estrutura tridimensional da ubiquitina Os terminais N e C estâc indicados, bem como os resíduos de lisma na posiçäo 48 e de glicina na posiçăo 76 .

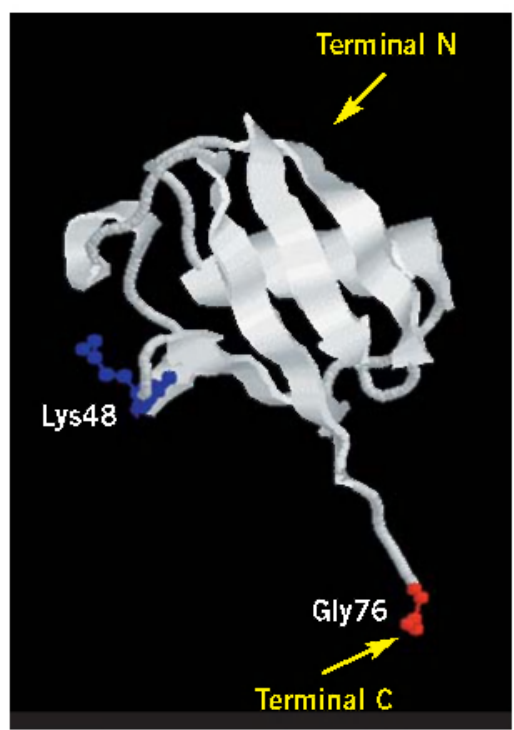

APFI correspondia ao polipéptido descrito anteriormente como ubiquitina.

Hershko e Ciechanover colocaram como hipótese que o factor APFI fosse uma subunidade de uma protease, ou um seu activador, existente na fracção 2. Para testar esta ideia marcaram radioactivamente ubiquitina purificada com ${ }^{125}$ e incubaram-na com as proteínas da fracção 2, na presença e na ausência de ATP. O resultado foi surpreendente. No ensaio com ATP, a pequena molécula de ${ }^{125}$-ubiquitina encontrava-se presente em fracções de massa molecular elevada após separação das proteínas por filtração em gel. Mais ainda, a associação de ${ }^{125} \mid$-ubiquitina às proteínas ocorria através de ligações amida, uma vez que os complexos de massa molecular elevada isolados eram estáveis a tratamentos com ácidos, bases, hidroxilamina, ou a fervura em presença de SDS e mercaptoetanol. Perante estes resultados, os consagrados cientistas reformularam a hipótese inicial e começaram a pensar que a ubiquitina poderia ligar-se, não a uma protease, mas às proteínas-substrato a serem digeridas, funcionando assim como um marcador selectivo de degradação das proteínas a que se encontrava ligada. De facto, quando várias proteínas-substrato do sistema proteolítico dependente de ATP foram testadas em presença de ${ }^{125}$-ubiquitina observou-se a conjugação covalente da ubiquitina a essas proteínas. A análise por SDS-PAGE dos substratos conjugados revelou a presença de bandas discretas correspondendo a uma, duas, três ou mais moléculas de ubiquitina ligadas a uma molécula de substrato. Foi nos Proceedings of the National Academy of Sciences of USA que este trabalho pioneiro foi publicado com um novo conceito de degradação de proteínas intracelulares: a conjugação covalente de moléculas de ubiquitina a uma proteína marca-a para degradação por uma protease que reconhece especificamente proteínas ubiquitiladas $(9,10)$.

Estudos subsequentes liderados por Hershko conduziram à caracterização bioquímica dos passos enzimáticos envolvidos no processo de ligação covalente da ubiquitina às proteínas substrato (ver abaixo). A descoberta da protease que reconhece proteínas ubiquitiladas, ou seja, do actualmente chamado proteassoma $26 \mathrm{~S}$, aconteceu no laboratório de Martin Rechsteiner (11).

Digno de citação é o trabalho desenvolvido no laboratório de Alexander Varshavsky na caracterização fisiológica deste sistema proteolítico em células animais e, principalmente, em levedura de padeiro. Entre 1984 e 1990 este grupo demonstrou a participação da via proteolítica dependente de ubiquitina no figura 2 Passos enzimáticos principais da via proteolítica dependente de ubiquitina/proteassoma. E1 - enzima activador de ubiouitina, E2 - enzima conjugador de ubiquitina, $E_{3}$ - ligase de ubiquitina-proteina, Ub-ubigutma ou grupo ubiquitil

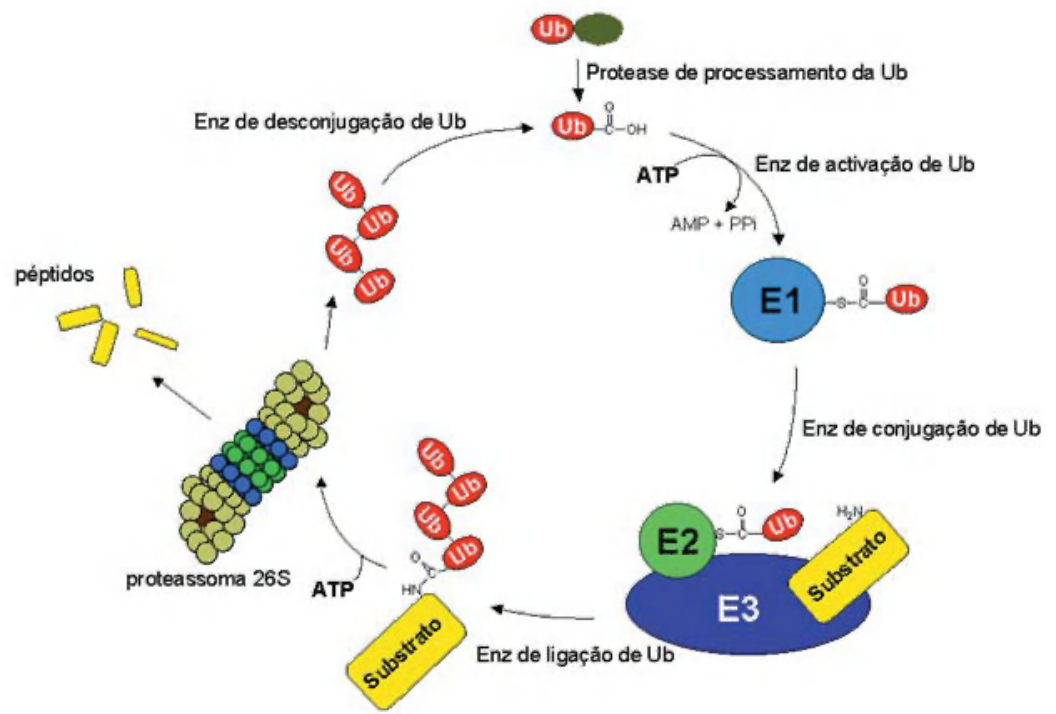


ciclo celular, na reparação do DNA, na resposta a stresses e na regulação da transcrição, bem como publicou a primeira caracterização de sinais de degradação apresentados pelas proteínas (the $\mathrm{N}$-end-rule) (12). Desde então muitos têm sido os cientistas de todo o mundo envolvidos na dissecção dos enzimas envolvidos na via proteolítica dependente de ubiquitina, na descoberta de novos substratos e na forma como esta participa nos processos celulares (ver referências nos artigos de revisão 12-16).

\section{Ubiquitina}

A ubiquitina é uma proteína constituída por 76 resíduos de aminoácidos. Encontra-se presente em todas as células eucariotas (e por isso o seu nome) e é uma das proteínas mais conservadas em termos de sequência, tanto que entre a levedura de padeiro e o homem existem apenas três resíduos diferentes

A ubiquitina é sintetizada na forma de precursores codificados por vários genes. Esses precursores são proteínas ribossomais fundidas com ubiquitina ou várias moléculas de ubiquitina ligadas entre si. O gene que codifica poli-ubiquitinas opera em condições de stress (por exemplo choque térmico) e origina várias moléculas de ubiquitina ligadas entre si através do terminal $\mathrm{C}$ da molécula anterior e o terminal $\mathrm{N}$ da molécula subsequente. As moléculas de ubiquitina são libertadas das suas formas precursoras através da acção de proteases de processamento específicas para a ubiquitina (ver enzimas de desubiquitilação), originando ubiquitina livre cujo terminal C é uma glicina (ver figura 1), essencial para o processo de activação pelo enzima E1.

\section{Ubiquitilação}

A ubiquitilação (ou conjugação com ubiquitina) consiste numa modificação pós-traducional reversível que se traduz na formação de uma ligação isopeptídica entre a ubiquitina e a proteína-substrato e envolve pelo menos a acção de três classes de enzimas: E1 (enzima activador da ubiquitina); E2 (enzimas conjugadores de ubiquitina) e E3 (ligases de ubiquitina-proteína), figura 2 .

Em primeiro lugar, ocorre a activação do grupo carboxílico da glicina existente no terminal $\mathrm{C}$ da ubiquitina, catalisada po E1. Este passo envolve a formação de um adenilato de ubiquitina intermediário (com a concomitante hidrólise de ATP) e a transferência da ubiquitina activada para o centro tiol do enzima E1 (com a libertação de AMP). Após esta reacção inicial, a ubiquitina activada é transferida, por transacilação, para um grupo tio de um segundo enzima, pertencente à família das proteínas E2. Estes ésteres de tiol, formados entre E2 e ubiquitina, são os dadores da ubiquitina para a formação da ligação isopeptídica entre o resíduo de glicina do terminal $\mathrm{C}$ da ubiquitina e grupos amina de resíduos de lisina das proteínas-substrato. Este passo requer a participação de um terceiro tipo de enzimas, designado por E3, responsáveis pela selecção da proteína substrato através do reconhecimento de um sinal de degradação existente nessa proteína. Note-se que alguns enzimas E2 poderão contribuir, também, para o reconhecimento da proteína substrato ubiquitilando-a na ausência de E3. Várias moléculas de ubiquitina podem ser adicionadas formando uma cadeia multi-ubiquitina. As proteínas assim modificadas podem sofrer degradação pelo proteassoma ou servir outras funções nas células tais como endocitose, tradução de sinais, actividade da cromatina e reparaçăo de DNA. O destino das proteínas-substrato parece ser determinado pelo número de ubiquitinas ligadas e o tipo de ligaçốes entre estas. 0 resíduo de lisina 48 da ubiquitina constitui o local preferencial de ligação de novas metades ubiquitil. A Lys 29 da ubiquitina é também utilizada para a formação de cadeias poli-ubiquitina. Ambas as cadeias via Lys 48 ou Lys 29 constituem cadeias que promovem a degradação da proteína-substrato pelo proteassoma, figura 3. No entanto, tanto a mono-ubiquitilação como a poli-ubiquitilação via

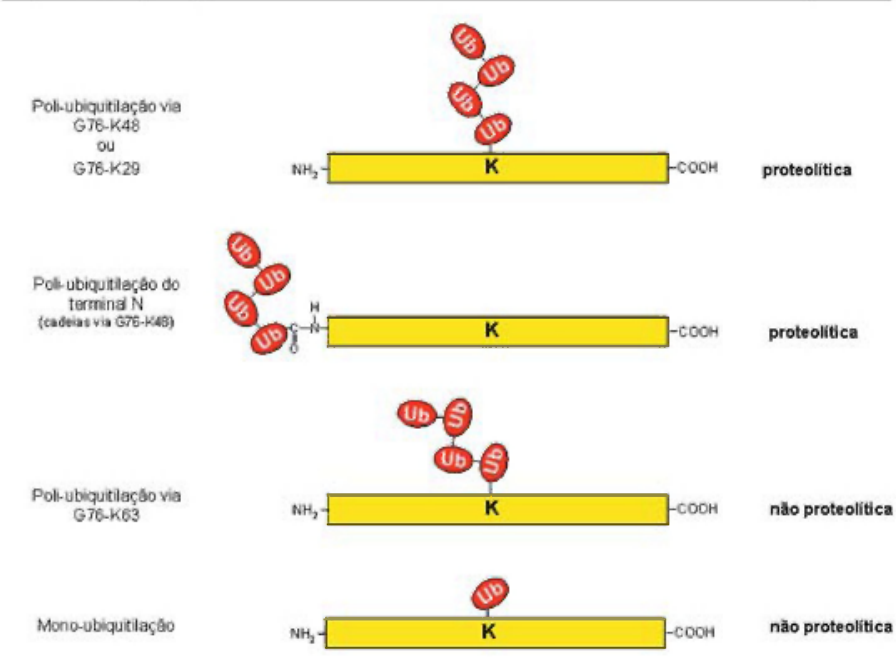


Lys63 da ubiquitina não servem funções proteolíticas, mas estão antes envolvidas na alteração da função do substrato ou na mediação de interacções proteína-proteína. Recentemente, foi demonstrado que algumas proteinas sofrem degradação após ubiquitilação do seu grupo amina do terminal N (chamada ubiquitilação do terminal N). A formação da cadeia multi-ubiquitina ocorre, como normalmente, via a Lys48 da ubiquitina.

\section{E1 - enzima activador da ubiquitina}

O enzima E1 é codificado por um único gene, cuja delecção provoca inviabilidade celular, embora em mamíferos sejam conhecidas duas isoformas, Ela e Elb, que resultam da iniciação da tradução em dois locais diferentes. O primeiro passo de ubiquitilação envolve a formação de um adenilato de ubiquitina intermediário (com a concomitante hidrólise de ATP) e a transferência da ubiquitina activada para o grupo tiol da cisteína do centro activo do enzima E1 (com a libertação de AMP). Cada enzima El pode no máximo transportar duas moléculas de ubiquitina, uma como tiol-éster e outra como adenilato. A ubiquitina activada é transferida para a cisteína do centro activo de E2.

\section{E2 - enzimas conjugadores de ubiquitina}

Ao contrário de E1, cada célula contém vários enzimas E2. Em levedura de padeiro existem onze enzimas E2 capazes de transportar ubiquitina, enquanto que em células de mamífero são conhecidas mais de trinta E2. Todos estes enzimas possuem um domínio muito conservado (UBC - ubiquitin conjugation) com cerca de 150 resíduos de aminoácidos contendo uma cisteína que é o centro aceitador da ubiquitina activada por E1. As diferenças situam-se nas regiões dos terminais $\mathrm{N}$ e $\mathrm{C}$, podendo nalguns casos existirem inserções no domínio UBC. Estas sequências estão envolvidas na interacção com os enzimas E3.

\section{E3 - ligases de ubiquitina-proteína}

Enquanto que os enzimas E2 têm grande semelhança nas suas sequências e estruturas, os enzimas E3 são pouco semelhantes entre si, em parte porque estes são responsáveis pelo reconhecimento de sinais de destruição nas proteínas substrato (ver secção sinais de degradação). Existem duas classes distintas de E3, figura 4. A primeira classe é caracterizada por ter um domínio designado HECT (homologous to the E6-AP protein's C-terminus). A proteína E6-AP foi a primeira ligase identificada desta classe e foi descoberta por participar na degradação da proteína supressora de tumores p53 ao interagir com a proteína E6 do papilomavírus humano (ver secção doenças relacionadas com a via). 0 domínio HECT é constituído por 80 resíduos de aminoácidos e inclui a cisteína do centro activo que forma uma ligação tiol com a ubiquitina. A segunda classe de E3 é definida pela existência de um domínio RING finger, assim designado, porque $O$ gene que codifica a primeira proteína descrita contendo este domínio tem o nome de "really interesting gene 1". O domínio RING finger possui a capacidade de quelatar dois iões de zinco, através dos seus 8 locais de coordenação constituídos por histidinas e cisteínas, e medeia interacções com as proteínas E2. As proteínas E3 pertencentes à última classe facilitam a transferência directa de ubiquitina de enzimas E2 para os substratos sem o envolvimento de um intermediário tiol-éster E3-Ub, como acontece com as E3 do tipo HECT. Encontram-se nesta situação Ub ligases envolvidas no ciclo celular como os complexos APC (anaphase promoting complex, uma E3 constituída por várias subunidades que permite a progressão do ciclo de divisão celular em vários pontos) e SCF-RING (E3 constituída por Skp1, Culina, uma subunidade variável com um domínio designado por F-boxe uma subunidade com um domínio RING). Embora algumas das E3 conhecidas sejam complexos constituídos por várias subunidades, outras ligases são formadas por uma única cadeia polipeptídica.

\section{Degradação das proteínas pelo proteassoma}

As proteínas multi-ubiquitiladas, após desenrolamento da sua estrutura, são degradadas pelo proteassoma 265 , uma protease multimérica dependente de ATP com $\sim 2000 \mathrm{kDa}$, constituída por dois complexos regulatórios 195 e por um complexo catalítico de $-700 \mathrm{kDa}$, designado por proteassoma 20S. Os figura 4 Tipos de ligases ubiquitina-proteina (E3). E3 do tipo "RING finger" facilitam a transferéncia directa de ubiquitina de E2 para substratos sem um intermediário tiol-éster E3-Ub. No caso da classe HECT, a ubiquitina forma una ligaçăo tiol-śster com E3 antés de ser transferida para a lisina na proteina substrato.

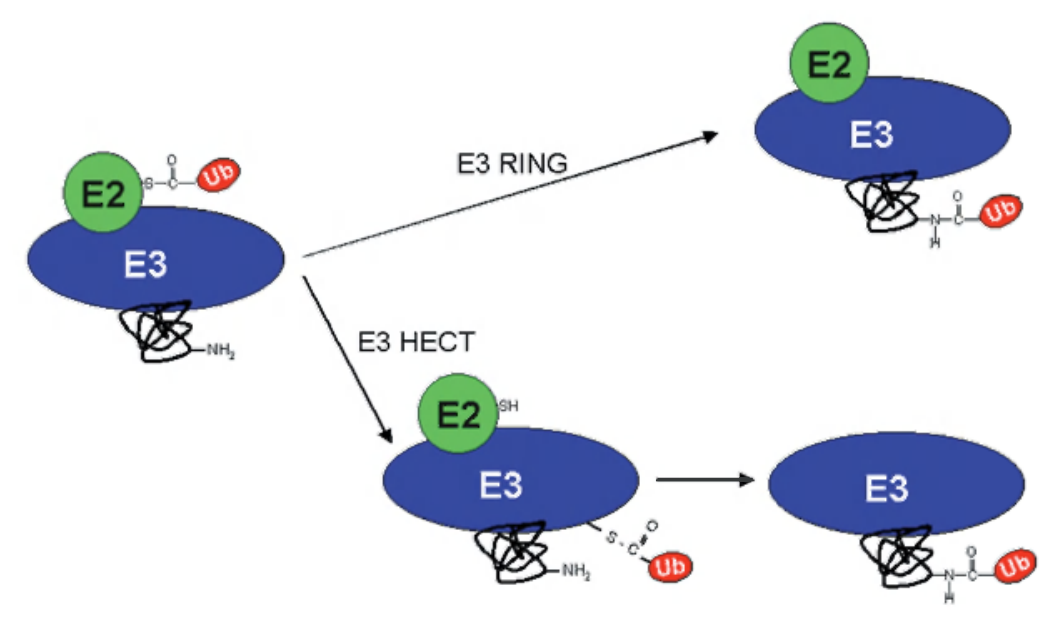


Thermoplasma

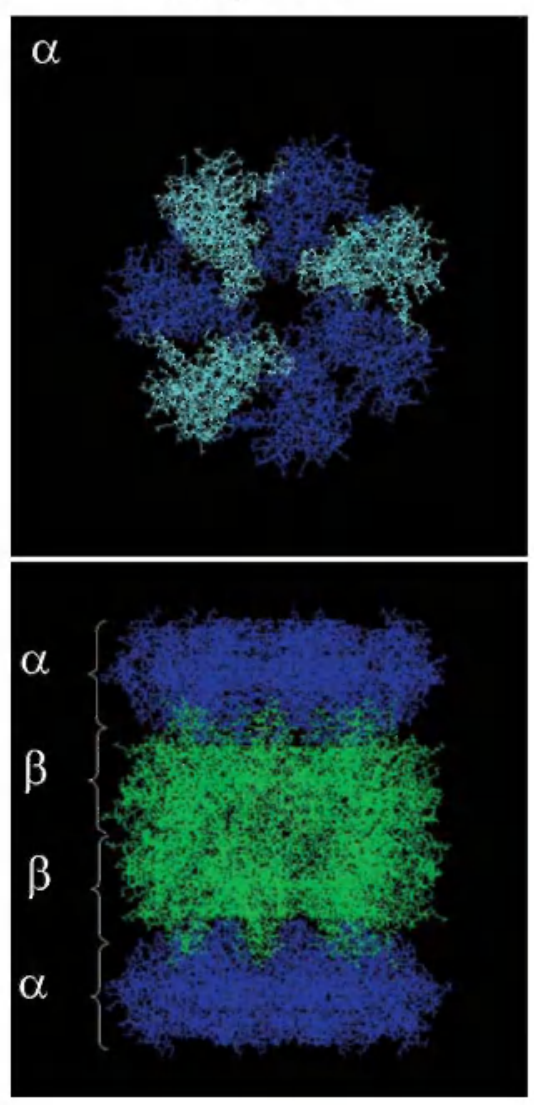

complexos regulatórios 19S, posicionados em ambas as extremidades do proteassoma 20S, compostos por várias ATPases e outras subunidades, são necessários para o reconhecimento específico de proteínas ubiquitiladas, seu desenrolamento e translocação para o interior da câmara catalítica. Na maioria dos casos o proteassoma degrada as suas proteínas-substrato reduzindo-as a pequenos péptidos (figura 2). Dado a sua estrutura, substratos e protease podem coexistir nos mesmos compartimentos, uma vez que, só após marcação com a ubiquitina, o substrato está preparado para sofrer hidrólise no interior do proteassoma.

Os proteassomas $20 \mathrm{~s}$ apresentam uma estrutura muito conservada e encontram-se presentes desde arqueobactérias até aos mamíferos. Este complexo proteolítico é essencial para a viabilidade das células eucariotas. O complexo eucariota é composto por 14 subunidades diferentes que, de acordo com a análise de homologias entre as sequências, podem ser agrupadas em sete do tipo $\alpha$

\section{S. cerevisiae}
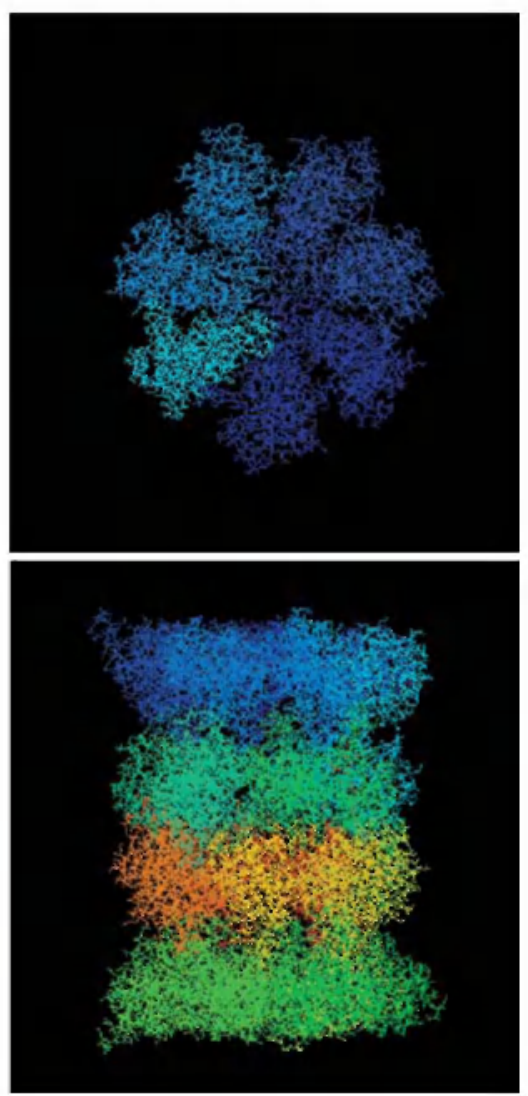

e sete do tipo $\beta$. Estas subunidades estão dispostas em forma de um cilindro composto por quatro anéis heptaméricos com as subunidades $\alpha$ ocupando os anéis periféricos e as subunidades $\beta$ os anéis centrais, figura 5. Este cilindro é atravessado por um túnel estreito que faz a comunicação entre três cavidades interiores. A cavidade central possui os centros catalíticos voltados para o interior. Os proteassomas eucariotas possuem pelo menos três actividades catalíticas diferentes, nomeadamente actividade pós-acídica (clivagem da ligação peptídica após um resíduo ácido), tríptica (clivagem após um resíduo básico) e quimotríptica (clivagem após um resíduo hidrófobo), cujos centros catalíticos se localizam em três subunidades $\beta$ distintas, $\beta 1, \beta 2$ e $\beta 5$ respectivamente. Estas subunidades que contêm os centros catalíticos possuem uma treonina no terminal N. Este resíduo age como um nucleofilo atacando as ligações peptídicas das proteínas-substrato. Nos vertebrados as subunidades com actividade catalítica constitutivas podem ser substituídas especificamente por subunidades catalíti- figura 5 Estrutura tridimensiona?

do proteassoma 205 de Thermoplasma acidophilum e de Saccharomyces cerevisiae Os painéis de cima mostram uma vista de topo dos anéis $\alpha$ da espécie mencionada Os painéis de baixo, evidenciam a estrutura em forma de barril formada por 4 anéis empithados. cas homólogas, $\beta 1 i$, $\beta 2 i$ e $\beta 5 i$ induzidas pelo interferão $\gamma$, sendo incorporadas durante a síntese e montagem de novos proteassomas no local das subunidades habituais. A incorporação destas subunidades altera a especificidade da clivagem das ligações peptídicas e coloca o proteassoma num papel central na produção de péptidos antigénicos a partir de proteínas de agentes patogénicos intracelulares, tais como bactérias ou vírus.

O acesso ao interior do proteassoma $20 S$ é bastante restrito. No caso de proteassomas bacterianos existe uma pequena abertura no centro dos anéis externos (anéis $\alpha$ ), no entanto, a análise da estrutura do proteassoma $20 \mathrm{~S}$ de levedura mostra que essa entrada se encontra preenchida pelos terminais $\mathrm{N}$ das subunidades $\alpha$, figura 5. Embora péptidos ou polipéptidos sem estrutura possam atravessar estas entradas e sofrer hidrólise no interior da cavidade catalítica, o proteassoma $20 \mathrm{~S}$ existe no citoplasma como que num estado latente. $A$ entrada de substratos mais complexos e 
a sua degradação necessita de complexos activadores $19 S$ que se ligam às extremidades do proteassoma $20 \mathrm{~S}$ originando o rearranjo dos terminais $\mathrm{N}$ das subunidades $\alpha$ que formam um poro de entrada. É nestes complexos activadores que se encontram os locais de reconhecimento das cadeias poli-ubiquitiladas das proteínas-substrato e as actividades de isopeptidase que libertam a ubiquitina das cadeias deixando-a livre para entrar em novo ciclo de conjugação. 0 substrato é então desenrolado e translocado atráves do proteassoma até chegar à cavidade central onde é degradado. As subunidades com actividade ATPásica da partícula $19 S$ são responsáveis por estes processos.

\section{Enzimas de desubiquitilação}

$\mathrm{Na}$ via proteolítica dependente de ubiquitina as moléculas de ubiquitina não se "gastam" durante a degradação das proteínas substrato, são sim recicladas através da acção de hidrolases de cisteína específicas. Além disso, os enzimas de desubiquitilação desempenham um papel único uma vez que podem reverter o destino das proteínas condenadas a degradação. Estes enzimas são responsáveis por processar os precursores inactivos da ubiquitina, reciclar ubiquitina de cadeias poli-ubiquitina conjugadas com proteínas-substrato, remover ubiquitina de aductos celulares e de manter o proteassoma livre de cadeias poli-ubiquitina que, obviamente, inibiriam a sua função. Existem duas classes: as proteases de processamento especificas para a ubiquitina e as hidrolases do terminal $\mathrm{C}$ da ubiquitina. As primeiras são responsáveis pela clivagem dos precursores de ubiquitina e de cadeias poli-ubiquitina gerando ubiquitina livre, enquanto que as segundas hidrolisam ligações éster e amida de pequenos aductos ligados ao terminal $\mathrm{C}$ da ubiquitina. Um destes enzimas (Doa4/Ubp4, na levedura de padeiro) encontra-se associado ao proteassoma $26 \mathrm{~S}$ e tem como função clivar a liğação isopeptídica existente entre a cadeia poli-ubiquitina e a lisina da proteína-substrato, facilitando a degradaçăo desta, enquanto que, outra proteína (Ubp 14, na levedura ou Isopeptidase T em mamíferos) é res- ponsável pelo desmantelamento da cadeia poli-ubiquitina.

\section{Sinais de degradação}

O tipo de resíduo de aminoácido que se encontra no terminal $\mathrm{N}$ da proteína foi o primeiro sinal de degradação das proteínas de semi-vida curta a ser descoberto ( $N$-end rule). Proteínas com resíduos, designados por destabilizadores, como a arginina ou a leucina, são reconhecidas pela E3 $\alpha$ ou $\mathrm{N}$-recognina (uma E3 do tipo RING finger) que, juntamente, com uma E2 específica medeiam a poli-ubiquitilação da proteína que é, então, rapidamente degradada pelo proteassoma.

Regiões de proteínas ricas em prolina $(P)$, Glutamato (E), serina (S) e treonina $(\mathrm{T})$, designadas por PEST, quando expostas à superfície duma proteína são também muitas vezes reconhecidas como sinais de destruição pela via proteolítica dependente de ubiquitina. A fosforilação do resíduo de serina ou de treonina nestas regiões parece mediar o reconhecimento da proteína por certas ligases do tipo SCF-RING. Outras proteínas apresentam uma sequência de 9 resíduos, perto do terminal $N$, chamada destruction box que é reconhecida por certas ligases.

\section{Funções da via proteolítica dependente da ubiquitina}

Em condições fisiológicas normais e em particular condições de stress ocorre o enrolamento incorrecto de proteínas, que ou são recuperadas por acção de chaperones moleculares, ou destruídas pela via dependente de ubiquitina. De facto, os níveis de expressão, tanto do gene que expressa poli-ubiquitina como de vários genes que expressam E2, aumentam quando se submetem células a diferentes tipos de stress.

A falta de apertado controlo do ciclo de divisão das células está implicada no desenvolvimento de tumores. A via proteolítica dependente de ubiquitina/proteassoma desempenha um papel muito importante pelo menos em três períodos do ciclo de divisăo celular. Na transiçăo G1/S, a iniciaçẫo da replicação do DNA é desencadeada pela degradação de um inibidor de uma cinase dependente de ciclina. Quando este inibidor sofre fosforilação, uma E3 (um complexo SCFRING) reconhece-o como substrato ocorrendo ubiquitilação e subsequente degradação. Durante a mitose, outra fase do ciclo celular, a securina, um inibidor da separina (uma endoprotease envolvida na separação dos cromatídeos), sofre ubiquitilação sendo depois degradada pelo proteassoma. Na fase final da mitose, as ciclinas características desta fase, bem como factores que controlam a desmontagem do fuso mitótico sofrem degradação pela via proteoIítica dependente de ubiquitina/proteassoma.

Uma outra função fisiológica importante desta via é a produção de péptidos antigénicos a partir de proteínas de bactérias ou vírus patogénicos. Os péptidos apresentados às células citotóxicas $T$ nas moléculas do complexo major de histocompatibilidade (MHC) de classe I são o resultado de proteólise limitada dos antigénios mediada pelo proteassoma. $O$ interferão $\gamma$ estimula este processo e induz a troca de subunidades catalíticas do proteassoma $20 S$ (ver degradação das proteínas pelo proteassoma). O sistema dependente de ubiquitina/proteassoma degrada indiscriminadamente tanto as proteínas celulares (self) como as estranhas (non-self). Os péptidos são então apresentados às células citotóxicas T, mas apenas os derivados das proteínas estranhas elicitam a resposta das células $T$.

A maioria dass proténás de secreção adquirem a sua estrutura tridimensional no retículo endoplasmático e são então enviadas para o local onde desempenham as suas funções. Proteínas mal-enroladas ou dissociadas devem ser selectivamente eliminadas evitando que sejam enviadas para os seus destinos finais. A degradação pelo proteassoma 265 déstas proteínas, tanto do lúmen como da membrana, necessita do retrotransporte para o citoplasma através do translocăo do ER (Sec61) e respectiva ubiquitilação por E2 e E3 ligadas à membrana do ER do lado citoplasmático.

A síntese do RNA mensageiro nos eucariotas é catalisada pelo enzima RNA polimerase II e depende de muitos factores 
de transcrição que controlam a sua actividade. Uma forma de regular o nível de certos factores de transcrição é através da sua ubiquitilação e subsequente degradação pelo proteassoma. A proteína p50, uma subunidade do NF-kB, um factor de transcrição que medeia a resposta inflamatória, tem como precursor o polipéptido p105, um substrato pouco usual do proteassoma. O domínio do terminal C do p105 é completamente degradado pelo proteassoma, enquanto que o domínio no terminal $\mathrm{N}$ contendo o p50 fica intacto. Neste caso o proteassoma funciona como protease de processamento não levando à degradação do substrato em pequenos péptidos.

O enzima Ubc2 (um dos treze E2 de levedura) foi o primeiro enzima da via dependente de ubiquitina a ser relacionado com uma função fisiológica, devido à sua identidade com a proteína anteriormente descrita como Rad6, um componente essencial na reparação do DNA. Rad6 participa na mono-ubiquitilação de uma subunidade da DNA polimerase (PCNA) envolvida na síntese e reparação do DNA. A endocitose de receptores da membrana celular é outro exemplo de um processo que envolve ubiquitilação, mas não a degradação da proteína-substrăto. A mono-ubiquitilaçãa dẹssaas proteínas é suficiente para que ocorra internalização destas proteínas e o seu transporte para o vacúolo.

\section{Doenças relacionadas com o mal funcionamento da via proteolítica dependente de ubiquitina/proteassoma}

Estando na base de vários processos celulares importantes, não é surpresa que o mal funcionamento desta via esteja implicado na origem de muitas doenças.

Em resposta a danos no DNA ou a pertubaçǒes celulares, como uma infecçăo viral, a progressắo do ciclo celular é inibida pela activação do supressor de tumores p53 (um activador da transcrição). Nas células normais, o p53 é uma proteína instável que é ubiquitilada pela ligase de ubiquitina Mdm2 (E3) e rapidamente degradada pelo proteassoma. Em células cujo DNA tenha sofrido danos ocorre a estabilização da proteína p53 e concomitante supressão da divisão celular para que os sistemas de re paração do DNA possam operar. Mais ainda, em situações em que os danos são muito grandes, a proteína p53 participa na indução de apoptose (morte celular) conduzindo à eliminação da célula. Alguns vírus, como por exemplo o papilomavírus humano (HPV) possuem no seu genoma um oncogene que codifica para uma proteína, designada por $\mathrm{E} 6$, que se associa a uma ubiquitina ligase, E6-AP (uma E3 com um domínio HECT), permitindo o reconhecimento do p53 e a sua posterior degradação, mais rápida ainda do que em condições normais. Pensa-se que a proteína E6 faz parte da estratégia viral para induzir a proliferação das células hospedeiras infectadas e impossibilitando a acção do p53 na indução de morte celular.

Numa grande variedade de doenças neurodegenerativas observa-se a acumulação de inclusões intracelulares de proteínas com mal-formações. Estão neste caso as doenças de Alzeihmer e Parkinson, a esclerose amiotrópica lateral (ALS), e outras doenças associadas à expansão de extensões de poliglutamina como a doença de Huntington ou ataxias espinocerebrais e a atrofia muscular espinobulbar. Embora as proteínas encontradas nestes agregados intracelulares são muitas vezes detectadas ligadas a ubiquitina e ao proteassoma, a ligação entre as patogenecidade e aberraçōes nả vià proteoolítica năo săo ainda claras. No entanto, nalgumas formas hereditárias da doença de Parkinson a patogenecidade desta doença está relacionada com mutações na proteína parkin, que é uma ligase de ubiquitina do tipo RING.

A fibrose quística e a atrofia muscular são também exemplos conhecidos do mal funcionamento da via proteolítica dependente de ubiquitina.

O impacto do conhecimento em detalhe da via proteolítica dependente de ubiquitina/proteassoma tem vindo a permitir o desenvolvimento de fármacos que permitem bloquear o sistemá. com o avanço do conhecimento de todos os componentes envolvidos em cada processo, o fármaco ideal será aquele que é dirigido especificamente às proteínas afectadas.

Agradecimentos

Aos Drs. António Marques e Ana Matias pela cuidadosa revisão do manuscrito. A FCT pelos projectos POCTI/32621/BME /2000 e POCTI/BME/47604/2002.

\section{Referências}

(1) Schoenheimer, R. in The dynamic State of Body Constituints. Harvard University Press, Cambridge, Massachusetts, 1942

(2) Simpson, M. V. J. Biol. Chem. 201 (1953) 143

(3) Schimke, R. e Doyle, D. Annu. Rev. Biochem. 39 (1975) 929

(4) Goldstein, G., Scheid, M., Hammerling,

U., Boyse, E. A., Schlesinger, D.H. e Niall,

D. Proc. Natt. Acad. Sci. USA 72 (1975) 11

(5) Goldknopf, I.L. e Busch, H. Proc. Natl. Acad. Sci. USA 74 (1977) 864

(6) Etlinger; J.D. e Goldberg, A.L. Proc. Natl. Acad. Sci. USA 74 (1977) 54

(7) Ciechanover, A., Hod, Y. e Hershko, A Biochem. Biophys. Res. Commun. 81 (1978) 110

(8) Wilkinson, K.D., Uban, M.K. e Haas, A.L. J. Biol. Chem. 255 (1980) 7529

(9) Ciechanover, A., Heller, H., Elias, S., Haas, A.L. e Hershko, A. Proc. Natl. Acad. Sci. USA 77 (1980) 1365

(10) Hershko, A., Clechanover, A. Heller, H., Hass, A.L. e Rose, I.A. Proc. Natt. Acad. Sci. USA 77 (1980) 1783

(11) Hough, R., Pratt, G. e Rechesteiner, M. J. Biol. Chem. 261 (1986) 2400

(12) Finley, D., Ciechanover, A. e Varshavsky, A. Cell 116 (2004) 29

(13) Pickart, C. Cell 116 (2004) 181

(14) Pickart, C. Annu. Rev. Biochem. 70 (2001) 503

(15) Hershko, A., Ciechanover, A. e Varshavsky, A. Nature Med. 6 (2000) 1073

(16) Hershko, A. e Ciechanover, A. Annu. Rev. Biochem. 67 (1998) 425 